\title{
ANATOMIA DA MADEIRA DE DUAS ESPÉCIES DE EUGENIA L. (MYRTACEAE) ${ }^{1}$
}

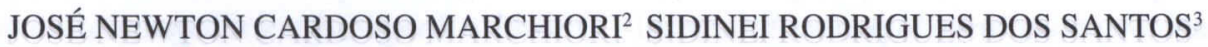

\section{RESUMO}

São anatomicamente descritas as madeiras de Eugenia rostrifolia D. Legrand e Eugenia uruguayensis Cambess. A diferenciação microscópica das madeiras requer o exame do arranjo de vasos e parênquima axial.

Palavras-chave: Eugenia rostrifolia, Eugenia uruguayensis, anatomia da madeira, Myrtaceae.

\section{SUMMARY}

[Wood anatomy of two species of Eugenia L. (Myrtaceae)].

The woods of Eugenia rostrifolia D. Legrand and Eugenia uruguayensis Cambess. are anatomically described. The microscopic segregation of both species needs the analysis of vessel and axial parenchyma arrangement. Key words: Eugenia rostrifolia, Eugenia uruguayensis, wood anatomy, Myrtaceae.

\section{INTRODUÇÃO}

O presente estudo visa à descrição microscópica da madeira de duas Mirtáceas da flora sul-rio-grandense.

Conhecida popularmente como batinga ou guapi, Eugenia rostrifolia D. Legrand é árvore de até $15 \mathrm{~m}$ de altura, com troncos retos, cilíndricos, de até $60 \mathrm{~cm}$ de diâmetro. A casca, espessa e rugosa, é marcada por fendas verticais muito características e a copa, alongada, tem densa folhagem verde-escura (Legrand \& Klein, 1969). Nativa do Alto Uruguai e da Encosta Sul da Serra Geral, a espécie é mais abundante em matas primárias de terrenos pedregosos. A madeira, ainda desconhecida sob o ponto de vista anatômico, serve para fazer varais e timão de

1 Recebido para publicação em 15-XII-2009 e aceito para publicação em 24-II-2010.

2 Engenheiro Florestal, Dr., bolsista de Produtividade em Pesquisa (CNPq - Brasil), Prof. Titular do Departamento de Ciências Florestais, Universidade Federal de Santa Maria. Santa Maria, RS, Brasil.marchiori@pq.cnpq.com.br

3 Biólogo, bolsista ( $\mathrm{CNPq}$ - Brasil), doutorando do Programa de Pós-Graduação em Eng. Florestal, Departamento de Ciências Florestais, Universidade Federal de Santa Maria. Sthurt.bio@gmail.com carroças, além de linhamentos e outras obras internas (Legrand \& Klein, 1969).

Eugenia uruguayensis Cambess. ocorre naturalmente no Paraguai, sul do Brasil, Uruguai e do nordeste da Argentina ao delta do Paraná e ilha de Martin Garcia (Lahitte \& Hurrel, 1994). Arvoreta de 4 a $12 \mathrm{~m}$ de altura, de esgalhamento ascendente, densa copa cimosa (Legrand \& Klein, 1969) e casca caduca (Brussa \& Grela, 2007), produz frutos oblongos, com cerca de 1 $\mathrm{cm}$ de comprimento, que tornam-se negros na maturação (Rotman, 2005). A madeira, utilizada apenas como lenha (Rotman, 2005), carece de descrição anatômica.

\section{REVISÃO DE LITERATURA}

Apesar do grande número de espécies e de sua importância fitofisionômica nas florestas sul-brasileiras (Klein, 1984), ainda são escassas as descrições anatômicas sobre madeiras de Mirtáceas, notadamente do gênero Eugenia L.

Para duas espécies da Floresta Atlântica, Soffiatti \& Angyalossy-Alfonso (1999) relacionam: porosidade difusa; vasos extremamente solitários; placas de perfuração simples; pontoações intervasculares alternas, guarnecidas; parênquima apotraqueal seriado; raios heterogêneos, estreitos; fibras de pontoações areoladas, com paredes espessas a muito espes- 
sas; e traqueídeos vasicêntricos, presentes. Com pouca variação anatômica, a separação das espécies baseou-se no arranjo do parênquima axial e na presença de cristais.

Em estudo de Eugenia copacabanensis, E. cuprea e E. macahensis, Marques et al. (2007) também observaram estruturas anatômicas homogêneas sob o ponto de vista qualitativo, diferindo as espécies, basicamente, pelo arranjo do parênquima axial e pelo agrupamento de vasos.

Da flora sul-riograndense, foram descritas as madeiras de Eugenia involucrata (Marchiori, 1984), Eugenia mansoi (Santos \& Marchiori, 2009a) e Eugenia uniflora (Santos \& Marchiori, 2009b). Para as três espécies, foram observados: porosidade difusa; poros solitários; placas de perfuração simples; pontoações intervasculares alternas; parênquima apotraqueal seriado; raios heterogêneos, estreitos; e presença de traqueídeos vasicêntricos. Entre os caracteres diferenciais, salienta-se a presença (ou ausência) de espessamentos espiralados em vasos e de ornamentações em pontoações intervasculares; o arranjo do parênquima axial; a natureza das fibras; e a ocorrência ou não de cristais no parênquima axial.

\section{MATERIAL E MÉTODOS}

O material em estudo consiste de duas amostras de madeira e respectivo material botânico, conservados no Herbário do Departamento de Ciências Florestais (HDCF), da Universidade Federal de Santa Maria sob os seguintes registros:

- Eugenia rostrifolia. Nova Roma do Sul, RS. HDCF 678.

- Eugenia uruguayensis. Taim, Rio Grande, RS. HDCF 5797.

Para o estudo microscópico das madeiras foram preparadas lâminas de cortes anatômicos e de macerado. Do material lenhoso foram extraídos três copos-de-prova $(3 \times 3 \times 3 \mathrm{~cm})$ da parte mais externa do lenho, próxima ao câm- bio, orientados para a obtenção de cortes anatômicos nos planos transversal, longitudinal radial e longitudinal tangencial. Um quarto bloquinho foi também preparado, com vistas à maceração.

Para as lâminas de cortes anatômicos, seguiuse a técnica padrão: amolecimento dos corposde-prova por fervura em água e realização de cortes em micrótomo de deslizamento, regulado na espessura nominal de $20 \mu \mathrm{m}$. Os cortes anatômicos foram tingidos com acridina-vermelha, crisoidina e azul-de-astra (Dujardin, 1964), desidratados em série alcoólica crescente $(30 \%$, $50 \%, 75 \%, 90 \%, 95 \%$, duas vezes álcool absoluto), diafanizados em xilol e montados em lâminas permanentes, com "Entellan".

Na maceração, seguiu-se o método de Jeffrey (Burger \& Richter, 1991), colorindo-se a pasta de fibras com safranina $1 \%$; a montagem de lâminas seguiu o anteriormente descrito, com a diferença de que as três primeiras etapas foram desenvolvidas sobre papel de filtro.

A descrição microscópica da madeira baseou-se nas recomendações do IAWA Comitee (1989). No caso da percentagem dos tecidos, foram realizadas 600 determinações ao acaso, com auxílio de contador de laboratório, conforme proposto por Marchiori (1980). A frequiência de poros foi obtida de forma indireta, usando-se um quadrado de área conhecida superposto a fotomicrografias de seções transversais das madeiras. As medições foram realizadas em microscópio Carl Zeiss, com ocular de escala graduada, no Laboratório de Anatomia da Madeira da Universidade Federal de Santa Maria.

$\mathrm{Na}$ citação de características quantitativas, os números entre parênteses equivalem aos valores mínimos e máximos observados; o valor que acompanha a média é o desvio padrão.

As fotomicrografias foram tomadas em microscópio Olympus cx40, equipado com câmera digital Olympus Camedia C3000. 


\section{DESCRIÇÕES ANATÔMICAS}

\section{1 - Eugenia rostrifolia Legr.}

Anéis de crescimento: distintos, delimitados por fina camada de fibras radialmente estreitas e, por vezes, por parênquima axial cristalífero ou alinhamento tangencial de poros.

Vasos: extremamente numerosos $(134 \pm 14$ $(112-150)$ poros $\left./ \mathrm{mm}^{2}\right)$, ocupando $25 \pm 6 \%$ do volume da madeira. Porosidade difusa. Poros solitários e em múltiplos radiais de 2 - 3 (5), raro em agrupamentos (racemiformes) de 2-4; circulares a ovais, muito pequenos $(42 \pm 11,6$ $(17-65) \mu \mathrm{m})$, de paredes espessas $(3,5 \pm 0,6$ $(2,5-5) \mu \mathrm{m}) \mathrm{e}$, por vezes, com tendência a alinhamento tangencial no início do anel de crescimento (Figura 1A, B). Elementos vasculares de comprimento médio $(514 \pm 105$ (270 - 740) $\mu \mathrm{m})$, com placas de perfuração simples, geralmente oblíquas, e apêndices geralmente em ambas as extremidades. Pontoações intervasculares alternas, circulares $(4 \pm 0,2(4,1$ $-4,6) \mu \mathrm{m}$ ), com abertura em fenda inclusa, ornamentada. Pontoações raio-vasculares com aréolas distintas, semelhantes às intervasculares, porém menores $(3 \pm 0,4(2,1-3,1) \mu \mathrm{m})$ e restritas às margens de raios. Espessamentos espiralados e conteúdos, ausentes.

Parênquima axial: muito distinto das fibras em corte transversal, representando $11 \pm 1,7 \%$ do volume da madeira; em arranjos apotraqueal difuso, difuso-em-agregados e, principalmente, em faixas tangenciais irregulares, com até 5 células de largura no lenho inicial, por vezes mais estreitas e descontínuas; raro paratraqueal escasso (Figura 1A, B). Parênquima marginal ocasionalmente presente e geralmente cristalífero. Séries parenquimáticas de $4-8$ (13) células, medindo $547 \pm 110(320-720) \mu \mathrm{m}$ de altura (Figura 1F). Cristais prismáticos em séries de até 24 unidades, em câmaras, por vezes distendidas.

Raios: muito numerosos $(20 \pm 1,4(22-18)$ raios $/ \mathrm{mm}$ ), com $1-3$, raro 4 células de largura (Figura 1E), ocupando $20 \pm 2,6 \%$ do volume da madeira. Raios multisseriados de $259 \pm 85$ $(120-450) \mu \mathrm{m}$ e 8 - 18 (21) células de altura; heterogêneos, reúnem células procumbentes, na parte multisseriada, e 1 - 4 (6) fileiras marginais de células eretas, quadradas e procumbentes mais altas do que as do corpo central (Figura 1C). A parte multisseriada é geralmente mais longa do que as margens unisseriadas (Figura $1 \mathrm{E}, \mathrm{F})$. Os unisseriados, com $172 \pm 97$ (50 420) $\mu \mathrm{m}$ e $1-12$, mais comumente $2-5$ células de altura. Raios axialmente fusionados, freqüentes. Células radiais de paredes disjuntas, presentes. Inclusões minerais, células envolventes e células perfuradas, ausentes. Conteúdo de cor avermelhada, pouco abundante.

Fibras: com pontoações areoladas e aberturas cruzadas, presentes nas faces radiais e tangenciais da parede. Tecido fibroso representando $44 \pm 4,7 \%$ do volume da madeira. Fibras de comprimento médio $(995 \pm 117(770-1290)$ $\mu \mathrm{m})$, com $19 \pm 2,6(14-25) \mu \mathrm{m}$ de largura e de paredes muito espessas $(6 \pm 1,1(4,3-8) \mu \mathrm{m})$ (Figura 1B). Fibras septadas, fibras gelatinosas e espessamentos espiralados, ausentes. Traqueídeos vasicêntricos, presentes.

Outros caracteres: variantes cambiais, tubos laticíferos e taniníferos, canais intercelulares, máculas medulares, células oleíferas, células mucilaginosas e estratificação, ausentes.

\section{2 - Eugenia uruguayensis Cambess.}

Anéis de crescimento: distintos, delimitados por fina camada de fibras radialmente estreitas (Figura 2A).

Vasos: muito numerosos $(50 \pm 8(44-62)$ poros $/ \mathrm{mm}^{2}$ ), ocupando $15 \pm 3,5 \%$ do volume da madeira. Porosidade difusa. Poros exclusivamente solitários, ovais a circulares, muito pequenos $(48 \pm 12(22-70) \mu \mathrm{m})$, de paredes espessas $(4,3 \pm 0,6(2,5-5) \mu \mathrm{m})$ e sem padrão definido de organização (Figura 2A,B). Elementos vasculares de comprimento médio (621 \pm $142(350-830) \mu \mathrm{m})$, com placas de perfuração simples, geralmente oblíquas e apêndices em ambas extremidades. Pontoações intervas- 

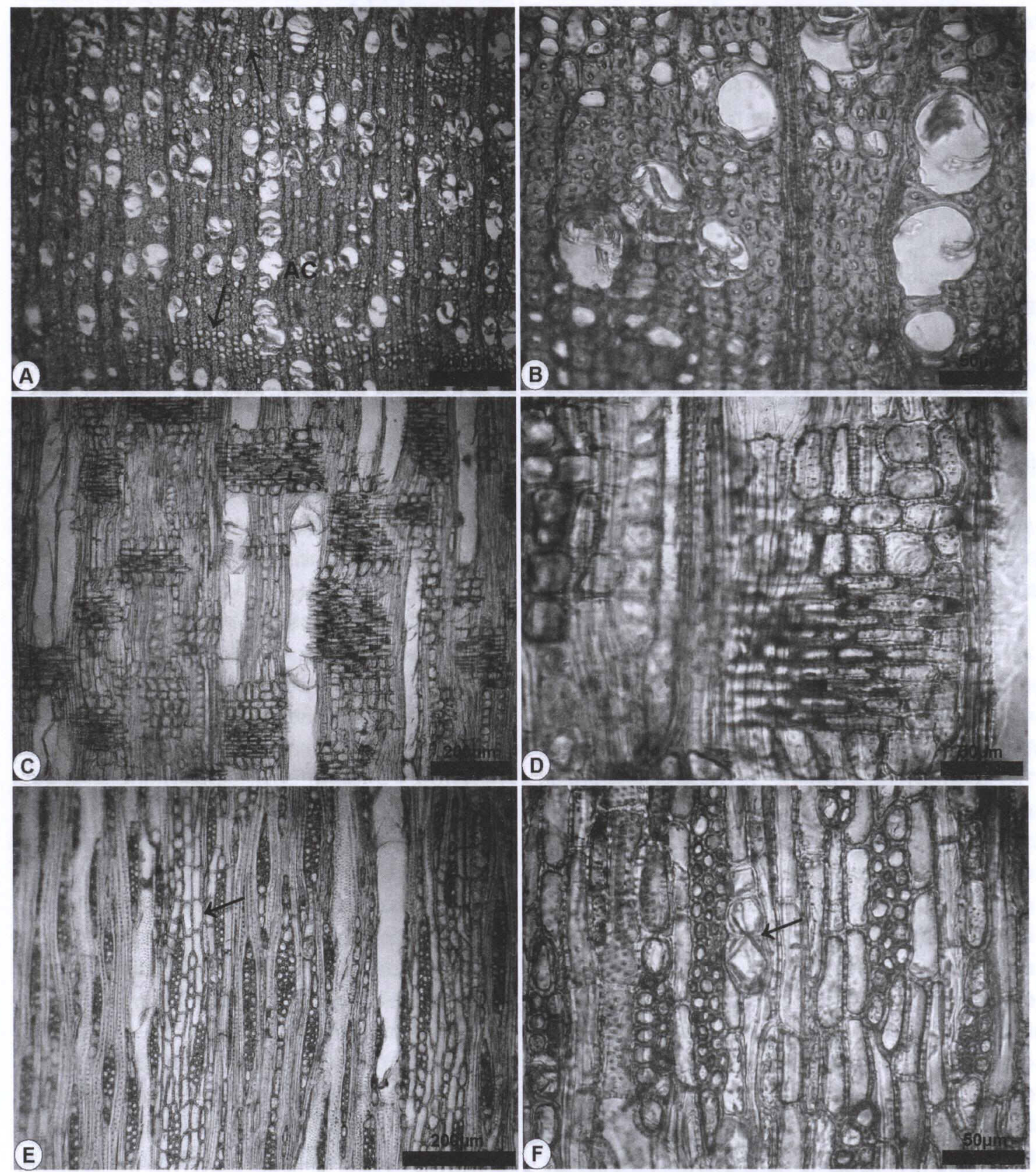

FIGURA 1 - Aspectos anatômicos da madeira de Eugenia rostrifolia Legr. A - Limite de anel de crescimento (AC), parênquima axial em faixas tangenciais (setas) e porosidade difusa, com poros solitários e em múltiplos radiais (seção transversal). B - Vasos, raios e fibras de paredes muito espessas, contrastantes com o parênquima axial (seção transversal). C - Raios heterogêneos, com margens de células eretas, quadradas e procumbentes mais altas do que no corpo central (seção longitudinal radial). D - Mesmos aspectos e plano anatômico da foto anterior, com maior aumento. E - Linhas vasculares, séries parenquimáticas axiais (seta) e fibras com pontoações areoladas (seção longitudinal tangencial). F - Cristais prismáticos (seta), no parênquima axial (seção longitudinal tangencial). 
culares alternas, circulares $(4,7 \pm 0,5(4-5)$ $\mu \mathrm{m})$, com abertura em fenda inclusa, não ornamentada. Pontoações raio-vasculares com aréolas distintas, semelhantes às intervasculares, porém menores $(3,2 \pm 0,4(2,6-4) \mu \mathrm{m})$ e restritas às margens de raios. Espessamentos espiralados e conteúdos, ausentes.

Parênquima axial: muito distinto das fibras em corte transversal, representando $20 \pm 3,6 \%$ do volume da madeira; nos arranjos apotraqueal difuso e, principalmente, difuso-em-agregados, além de paratraqueal escasso (Figura 2A, B). Séries parenquimáticas de $538 \pm 111(300-750)$ $\mu \mathrm{m}$ de altura (Figura 2F) e (2) $4-5$ (8) células. Cristais prismáticos grandes, em séries de 2 4, até 7 unidades quando menores, em câmaras distendidas do parênquima axial.

Raios: muito numerosos $(19 \pm 1,6(16-21)$ raios $/ \mathrm{mm}$ ), com 1 - 3 células de largura (Figura $2 \mathrm{E}$ ), ocupando $19 \pm 4,1 \%$ do volume da madeira. Raios multisseriados com $362 \pm 145$ (150 - 750) $\mu \mathrm{m}$ e $5-19$, mais comumente $8-12$ células de altura; heterogêneos, reúnem células procumbentes, na parte multisseriada, e $1-5$ (6) fileiras marginais de células eretas ou quase exclusivamente eretas (Figura 2C). A parte multisseriada é geralmente mais longa do que as margens unisseriadas (Figura 2E, F). Os unisseriados, com $205 \pm 118(70-530) \mu \mathrm{m} \mathrm{e} 1$ - 4 (6) células de altura. Raios axialmente fusionados, freqüentes. Células radiais de paredes disjuntas, presentes. Inclusões minerais, células envolventes, células perfuradas e conteúdos, ausentes.

Fibras: com pontoações areoladas e aberturas cruzadas, presentes nas faces radiais e tangenciais da parede. Tecido fibroso representando $46 \pm 3,6 \pm$ do volume da madeira. Fibras de comprimento médio (1236 \pm 168 (870 1470) $\mu \mathrm{m})$, com $17 \pm 1,9(15-20) \mu \mathrm{m}$ de largura e de paredes muito espessas $(5 \pm 0,8(4-7)$ $\mu \mathrm{m})$ (Figura 2B). Fibras septadas, fibras gelatinosas e espessamentos espiralados, ausentes. Traqueídeos vasicêntricos, presentes.
Outros caracteres: variantes cambiais, tubos laticíferos e taniníferos, canais intercelulares, células oleíferas, células mucilaginosas e estratificação, ausentes. Máculas medulares, ocasionais.

\section{ANÁLISE DA ESTRUTURA ANATÔMICA}

As principais características anatômicas observadas no material em estudo coincidem com o referido por Record \& Hess (1949) e Metcalfe \& Chalk (1972) para o conjunto das Myrtaceae: porosidade difusa; vasos principalmente solitários; placas de perfuração simples; pontoações intervasculares alternas; raios heterogêneos, estreitos; fibras com pontoações areoladas; e presença de traqueídeos vasicêntricos. Apesar desta semelhança estrutural, as duas espécies podem ser facilmente separadas com base em aspectos microscópicos da madeira.

Eugenia rostrifolia distingue-se pela presença de parênquima cristalífero e alinhamento tangencial de poros no limite de anéis de crescimento, pelos poros em múltiplos radiais de 2 -3 e alguns racemiformes, além dos solitários, bem como pelo parênquima axial em faixas tangenciais irregulares, com até 5 células de espessura. Em Eugenia uruguayensis, por sua vez, os anéis de crescimento são delimitados apenas por fibras radialmente estreitas, os poros são exclusivamente solitários e o parênquima axial segue os arranjos apotraqueais difuso, difuso-em-agregados e paratraqueal escasso, não ocorrendo faixas tangenciais. Cabe ressaltar que este conjunto de caracteres diferenciais é o mesmo utilizado por Soffiatti \& Angyalossy-Alfonso (1999) e por Marques et al. (2007), para a segregação de outras espécies brasileiras do mesmo gênero botânico.

\section{REFERÊNCIAS BIBLIOGRÁFICAS}

BRUSSA SANTANDER, C.A.; GRELA GONZÁLEZ, I.A. Flora arbórea del Uruguay. Con énfasis en las especies de Rivera y Tacuarembó. Montevideo: COFUSA, 2007. 542 p. 


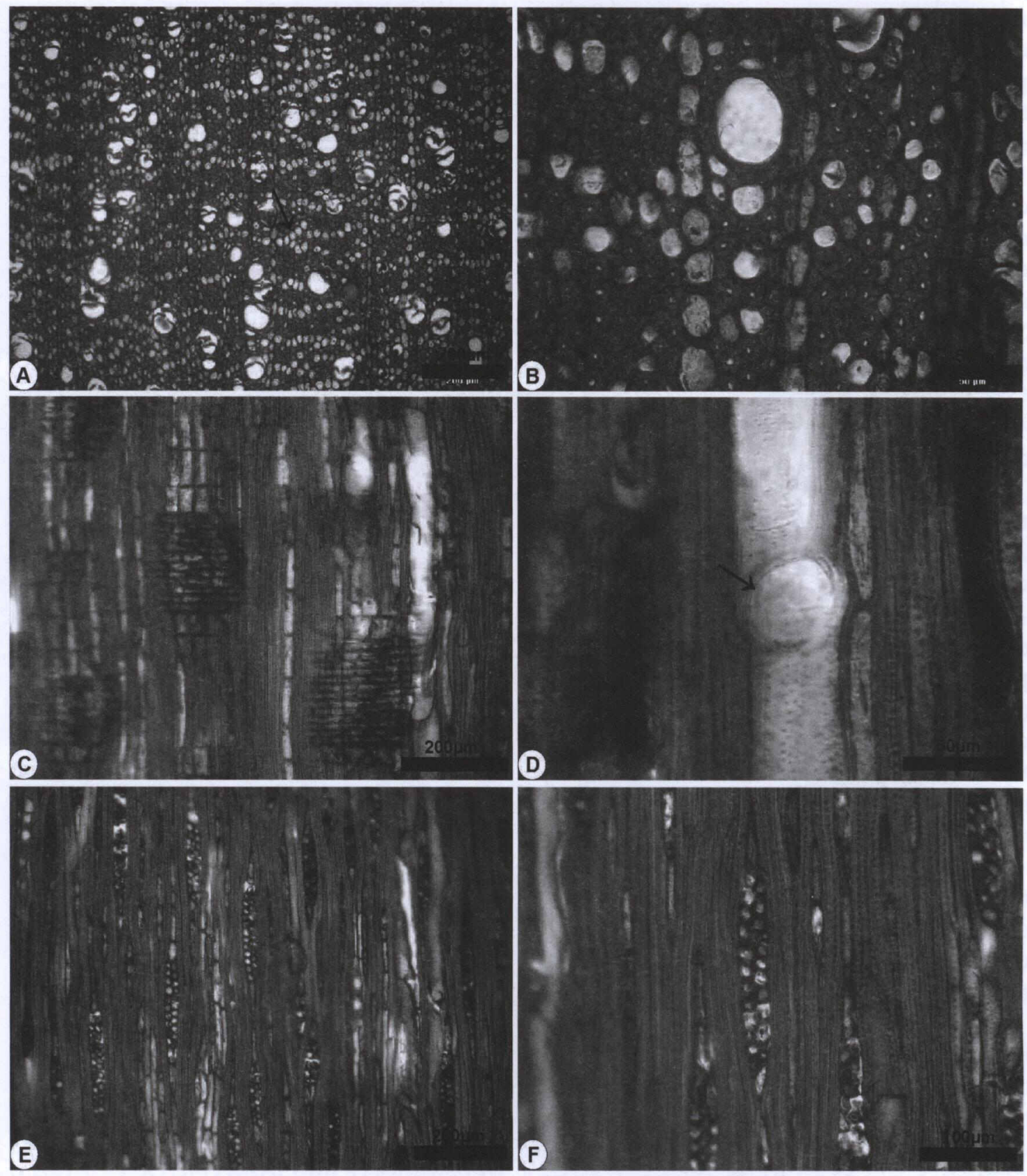

FIGURA 2 - Aspectos anatômicos da madeira de Eugenia uruguayensis. A - Porosidade difusa, vasos solitários, parênquima axial (seta) e fibras de paredes muito espessas (seção transversal). B - Mesmos aspectos e plano anatômico da foto anterior, com maior aumento. C - Raios heterogêneos, em seção longitudinal radial. D - Placa de perfuração simples (seta), em seção longitudinal radial. E - Raios com 1-3 células de largura, séries de parênquima axial e fibras de paredes espessas, em seção longitudinal tangencial. F - Mesmos aspectos e plano anatômico da foto anterior, com maior aumento. 
BURGER, L.M.; RICHTER, H.G. Anatomia da madeira. São Paulo: Ed. Nobel, 1991. 154 p.

DUJARDIN, E.P. Eine neue Holz-Zellulosenfaerbung. Mikrokosmos, n. 53, p. 94, 1964.

IAWA COMITTEE. IAWA list of microscopic features for hardwood identification. IAWA Bulletin, v. 10, n. 3, p. 218-359, 1989.

KLEIN, R.M. Importância sociológica das Mirtáceas em florestas rio-grandenses. Anais do XXXIV Congresso Nacional de Botânica (Porto Alegre), 1984. p. 367-375.

LAHITTE, H.B.; HURRELL, J.A. Los árboles de la isla Martín García. Buenos Aires: Laboratórios Roemmers, 1994. 135 p.

LEGRAND, C.D.; KLEIN, R.M. Mirtáceas. In: REITZ, P.R. Flora Ilustrada Catarinense. Itajaí: Herbário Barbosa Rodrigues, 1969. 216 p.

MARCHIORI, J.N.C. Estudo anatômico do xilema secundário e da casca algumas espécies dos gêneros Acacia e Mimosa, nativas no Estado do Rio Grande do Sul. 186 f. Dissertação (Mestrado em Engenharia Florestal) - Universidade Federal do Paraná. Curitiba, 1980.

MARCHIORI, J.N.C. Anatomia da madeira de
Eugenia involucrata DC. (Myrtaceae). Ciência e Natura, Santa Maria, v. 6, p. 127-136, 1984.

MARQUES, P.A.; ARAUJO, G.U.C.; BARROS, C.F.; CALLADO, C.H. Anatomia do lenho de três espécies de Eugenia L. (Myrtaceae) de mata e restinga. Revista Brasileira de Biociências, v. 5, p. 801-803, 2007.

ROTMAN, A.D. Myrtaceae, Mirtáceas. In: BURKART, A.; BACIGALUPO, N.M. Flora Ilustrada de Entre Ríos (Argentina). Buenos Aires: Colección Científica del I.N.T.A., 2005. Tomo VI, IV. p. 472-500.

SANTOS, S.R. dos; MARCHIORI, J.N.C. Anatomia do xilema secundário de Eugenia mansoi $\mathrm{O}$. Berg (Myrtaceae). Balduinia, Santa Maria, n. 16, p. 6-12, 2009a.

SANTOS, S.R. dos; MARCHIORI, J.N.C. Anatomia da madeira de Eugenia uniflora L. (Myrtaceae). Balduinia, Santa Maria, n. 17, p. 11-16, 2009 b.

SOFFIATTI, P.; ANGIALOSSY-ALFONSO, V. Estudo anatômico comparativo do lenho e da casca de duas espécies de Eugenia L. (Myrtaceae). Revista Brasileira de Botânica, São Paulo, v. 22, n. 2, p. 175-184, 1999. 